\title{
Reference Value of Normal Amniotic Fluid Index in Second and Third Trimester among Sudanese Pregnant Ladies
}

\author{
Mowada Burai ${ }^{1}$, Ibrahim Daoud ${ }^{2}$, Mohamed Adam $^{3}$ \\ ${ }^{1}$ (Collage of Radiological Sciences and Medical Imaging, \\ Alzaeim Alazhari University P.O. Box1432 Khartoum North, Sudan) \\ ${ }^{2}$ (Collage of Medicine Alneelain University P.O. Box 84 Khartoum, Sudan) \\ ${ }^{3}$ (Collage of Applied Medical Sciences Radiological Science Department, \\ King Khalid University Kingdom of Saudi Arabia P.O. Box 61481, Abha)
}

\begin{abstract}
:
Amniotic fluid index (AFI) is one of the major and deciding components of fetal biophysical profile and it can predict pregnancy outcome. The aims of this study were to evaluate the AFI in second and third trimester as well as to establish local reference value for Sudanese.

The study included 457 normal pregnant Sudanese ladies. The study was conducted at Omdurman Military Hospital during the period from 2010 to 2013. Ultrasound was done by using Toshiba ultrasound machine fitted with 3.5MHZ convex probe. Amniotic fluid volume (AFV) was measured by amniotic fluid index (AFI). The mean AFI was $13.37 \mathrm{~cm}$ at 24 weeks of gestations then it reached the peak of $13.69 \mathrm{~cm}$ at 26 weeks and gradually declined to $6.24 \mathrm{~cm}$ at 40 weeks. Normative range of amniotic fluid index values for second and third trimester for Sudanese pregnant ladies was established. Sudanese (AFI) value was found to be different from other populations.
\end{abstract}

Keywords: Amniotic Fluid Index; Ultrasonography; Third Trimester

\section{Introduction}

Amniotic fluid volume (AFV) is an important parameter to assess fetal growth and development. So that amniotic fluid is vital to the well-being of the fetus, it cushions the fetus from injury, helps prevent compression of the umbilical cord, and its bacteriostatic action helps prevent infection of the intra-amniotic environment. The quantity of amniotic fluid at any time in gestation is the product of water exchange between the mother, fetus, and placenta, and is maintained within a relatively narrow range. Disorders of this regulatory process can lead to either polyhydramnios or oligohydramnios. (Philip, 2000).Ultrasound is a useful method to identify amniotic fluid volume by measuring one large vertical pocket (SVP) or four quadrants in the uterus amniotic fluid index (AFI). (Cunningham et al, 2005).

Normal amniotic at 12 weeks' gestation, the average volume is $60 \mathrm{ml}$, by 16 weeks, when genetic amniocentesis is often performed; the mean volume is $175 \mathrm{ml}$. From 20 weeks on, there is greater variance of amniotic fluid volume. Based on numerous studies amniotic fluid volume increases steadily throughout pregnancy to a maximum of 400-1200 ml at 34-38 weeks; however, wide variation does exist. (Abramovich, 1970, Brace et al, 1961), after 38 weeks, fluid volume declines by approximately $125 \mathrm{ml} / \mathrm{week}$, to an average volume of $800 \mathrm{ml}$ at 40 weeks. After 43 weeks, this volume is reduced to $250 \mathrm{ml}$. (Brace et al, 1989, Elliott et al, 1961). The normal amount of amniotic fluid when measuring the large single vertical pocket (SVP) is between $2-8 \mathrm{~cm}$, when amount of fluid is $>8 \mathrm{~cm}$ it called polyhydramnios and when it $\langle 2 \mathrm{~cm}$ called oligohydramnios, if measuring four quadrants the normal values between $8 \mathrm{~cm}$ to $24 \mathrm{~cm},<8 \mathrm{~cm}$ is oligohydramnios and $>24 \mathrm{~cm}$ is polyhydramnios, this method of measurement called amniotic fluid index (AFI). Causes of fluid volume abnormalities are gastrointestinal obstruction, neural tube defect diabetes militias, birth defect involving the kidney and urinary tract intrauterine growth retardation. (Cunningham et al, 2005).

As the AFI differs according to race; to the best of our knowledge there is no standard reference values was measured for Sudanese. This study aimed to established reference standers of AFV by measuring the AFI in normal Sudanese pregnant ladies in second and third trimesters.

\section{Materials and Methods}

This was observational cross- sectional study conducted in Omdurman Military Hospital. Data were collected during the period from 2010 to 2013. Toshiba ultrasound machine UP-895 fitted with probe frequency of $3.5 \mathrm{MH}$ was used. The study included 457 normal pregnant ladies in second and third trimesters. There is no normal pregnant women identification or detail was published. Ladies were positioned in supine position. The ultrasound gel was applied in the lower abdomen, amniotic fluid volume measuring by amniotic fluid index (AFI). Amniotic fluid index was measured by dividing the uterus into four quadrant using linea nigra as 
vertical axis and umbilicus as horizontal axis with probe in longitudinal axis of the mother and perpendicular to the floor, the pocket must be free of any fetal part or umbilical cord, the sum of four quadrant called AFI (this method is similar to the method done by (Elsafi etal, 2013).Data analyses was performed with statistical package for social science (SPSS) program, tables of amniotic fluid index and p-value for testing the result were prepared

\section{Results}

Total of 457 normal pregnant ladies were included with the range of maternal age from 20 to 50 years, the amniotic fluid index was measured from 24- 40 weeks, table 1 and 2 presented the results.

Table (1) Mean amniotic fluid index of normal pregnant Ladies

\begin{tabular}{|l|l|l|l|l|}
\hline Age /(weeks) & Mean & Standard Deviation & Minimum & Maximum \\
\hline $\mathbf{2 4}(\mathbf{n}=\mathbf{6})$ & 13.37 & 3.24 & 9.3 & 17.12 \\
\hline $\mathbf{2 5}(\mathbf{n}=\mathbf{4})$ & 12.92 & 5.04 & 9.49 & 20.24 \\
\hline $\mathbf{2 6}(\mathbf{n}=\mathbf{1 0})$ & 13.69 & 4.63 & 7.65 & 21.64 \\
\hline $\mathbf{2 7}(\mathbf{n}=\mathbf{8})$ & 13.05 & 4.09 & 8.84 & 21.69 \\
\hline $\mathbf{2 8}(\mathbf{n}=\mathbf{1 1})$ & 13.28 & 1.79 & 10.56 & 16.59 \\
\hline $\mathbf{2 9}(\mathbf{n}=\mathbf{1 4})$ & 12.23 & 3.16 & 6.63 & 19.01 \\
\hline $\mathbf{3 0}(\mathbf{n}=\mathbf{3 2})$ & 11.87 & 3.83 & 6.42 & 21.17 \\
\hline $\mathbf{3 1}(\mathbf{n}=\mathbf{2 8})$ & 11.12 & 3.05 & 6.20 & 17.16 \\
\hline $\mathbf{3 2}(\mathbf{n}=\mathbf{4 1})$ & 10.70 & 3.02 & 5.09 & 16.81 \\
\hline $\mathbf{3 3}(\mathbf{n}=\mathbf{5 2})$ & 10.74 & 3.65 & 4.58 & 18.69 \\
\hline $\mathbf{3 4}(\mathbf{n}=\mathbf{7 2})$ & 10.46 & 3.59 & 6.13 & 20.67 \\
\hline $\mathbf{3 5}(\mathbf{n}=\mathbf{5 0})$ & 10.44 & 3.91 & 5.01 & 18.07 \\
\hline $\mathbf{3 6}(\mathbf{n}=\mathbf{6 8})$ & 10.17 & 4.59 & 2.88 & 20.91 \\
\hline $\mathbf{3 7}(\mathbf{n}=\mathbf{3 0})$ & 10.03 & 3.57 & 2.92 & 16.82 \\
\hline $\mathbf{3 8}(\mathbf{n}=\mathbf{2 3})$ & 9.88 & 4.08 & 3.53 & 17.38 \\
\hline $\mathbf{3 9}(\mathbf{n}=\mathbf{3})$ & 9.75 & 9.76 & 3.03 & 20.95 \\
\hline $\mathbf{4 0}(\mathbf{n}=\mathbf{5})$ & 6.42 & 3.24 & 3.00 & 9.55 \\
\hline $\begin{array}{l}\text { Overall } \\
\text { Mean (n=457) }\end{array}$ & $\mathbf{1 0 . 8 0}$ & $\mathbf{3 . 8 9}$ & $\mathbf{2 . 8 8}$ & $\mathbf{2 1 . 6 9}$ \\
\hline
\end{tabular}

Table (2) Gestational age classes and specific mean amniotic fluid index ( $5^{\text {th }}$ and $95^{\text {th }}$ percentiles)

\begin{tabular}{|l|l|l|l|l|}
\hline GA weeks & No. of subjects & Mean AFI $(\mathbf{c m})$ & $\mathbf{5}^{\text {th }}$ percentile & $\begin{array}{l}\mathbf{9 5}^{\text {th }} \\
\text { percentile }\end{array}$ \\
\hline $\mathbf{2 4 - 2 9}$ & 53 & 13.09 & 7.932 & 20.912 \\
\hline $\mathbf{3 0 - 3 4}$ & 225 & 10.98 & 8.601 & 21.567 \\
\hline $\mathbf{3 5 - 3 9}$ & 174 & 10.05 & 11.194 & 21.143 \\
\hline $\mathbf{4 0}$ & 5 & 6.42 & 8.056 & 21.368 \\
\hline \multicolumn{6}{|l|}{ Difference in the mean AFI } & $\begin{array}{l}\mathbf{0 . 8 1 3 ,} \\
\text { (no significant difference) }\end{array}$ \\
\hline
\end{tabular}

\section{Discussion}

Amniotic fluid production and regulation is a complex and dynamic process involving the fetus, placenta, and mother. Amniotic fluid volume gradually increases till 32-34 weeks of gestation and thereafter there is a gradual reduction till term. ( Brace et al, 1989, Moore et al, 1990) .The third trimester AFI values are proportionate to fetal urine production (Magann et al,2011, Lee et al,2007), and hence in normal range indicate good placental perfusion and fetal nutrient and oxygen transfer. Hence monitoring the AFI has become a standard of antenatal care.

There is wide variation in reference standards for mean AFI values according to population, race, environment, maternal size and intra uterine volume. The etiologies of relative reduction in amniotic fluid volume toward term and in uncomplicated post term pregnancies remain unclear. (Sherer et al, 2002).

Table (1) provides mean amniotic fluid index in normal pregnant ladies. It showed that at 24 weeks gestational age means AFI was $13.37 \mathrm{~cm}$, at 26 weeks it was $13.69 \mathrm{~cm}$, and at 40 weeks it was $6.42 \mathrm{~cm}$. The AFI reached to the maximum value at 26 weeks of gestation, and then gradually decreased at the term. Comparing with other populations ; studies showed that in Nigerian population; the mean of normal amniotic fluid index in 20 weeks gestation was $17.18 \mathrm{~cm}$ and reached the peak at 26 weeks of gestation with AFI of $20.39 \mathrm{~cm}$ and gradually declined at 42 weeks gestation with AFI of $8.37 \mathrm{~cm}$. (Chama et al, 2001). In Indian population an analysis of AFI estimation was undertaken in 517 Indian women with normal pregnancy between 16 and 42 weeks of gestation. The median reached its peak at the $27^{\text {th }}$ week of gestation. They observed approximately $6 \mathrm{~cm}$ as the lower limit of normal (5th percentile) and approximately $18 \mathrm{~cm}$ (95th percentile) as upper limit of normal AFI at term. (Chang et al, 2007). 
In Iranian population amniotic fluid index was studied in 489 normal pregnant women between 20 to 42 weeks. It reached its peak at the $27^{\text {th }}$ week of gestation $(14.6 \mathrm{~cm})$ and gradually declined at 41 week of gestation $(10.9 \mathrm{~cm})$. The mean $( \pm \mathrm{SD})$ AFI was $13.26 \pm 4.59$ (range: $5.1-26.1) \mathrm{cm}$. The mean $( \pm \mathrm{SD})$ AFI was $12.1 \pm 1.6 \mathrm{~cm}$ (Confidence Interval 95\%: 8.9-15.3) at the 20th week, increased to $14.6 \pm 1.2 \mathrm{~cm}$ (CI 95\%: 12.2-17) at the 27th week, and then declined to $10.9 \pm 1.2$ (CI 95\%: 8.5-13.3) at the 41 week. (Chamberlain et al, 1984). Table (2) showed that different values of amniotic fluid index at 5th percentile and 95th percentile, the percentile ranged from $7.93,20.91$ at (24- 29) weeks to 8.60, 21.56 at (30-34) weeks to $11.19,21.14$ at (35-39) weeks to $8.05,21.36$ at 40 weeks.

This study harmonized with the findings of the study done by Chama CM, et al, Who studied amniotic fluid index in normal pregnancy in Nigerian population and disagree with other studies. (Chang et al, 2007, Chamberlain et al, 1984).

\section{Conclusion}

The study concluded that the Sudanese AFI values differ from the Asian populations and consigned with the African populations results. We suggested the findings to be due to racial and ethnicity differences. A Sudanese Local reference values for AFI were established.

\section{Acknowledgements}

I gratefully thank Dr. Caroline Edward Ayad, Associate Professor of Diagnostic Radiology, Sudan University of Science and Technology, College of Medical Radiological Science ,for her help, support, motivation, perpetual optimism, and for providing comments, discussion and guidance.

\section{References}

[1]. Abramovich DR: Fetal factors influencing the volume and composition of liquor amnii. J Obstet Gynaecol Br Commonw 77: 865, 1970

[2]. Brace RA, Wolf EJ: Normal amniotic fluid volume changes throughout pregnancy. Am J Obstet Gynecol 161: 382, 1989

[3]. Chama CM, Bobzom DN.A longitudinal study of amniotic fluid index inNormal pregnancy in Nigerian women. Int JGynecolObstet;72:223-7. 2001

[4]. Chamberlain PF, Manning FA, Morrison I, Harman CR, Lange IR. Ultrasound evaluation of amniotic fluid index in Iranian population. Am J Obstet Gynecol;150:250-4.1984

[5]. Cunningham, F.G. et al. Disorder of amniotic fluid volume, in : Williams Obstetrics $22^{\text {nd }}$ Edition, New york, McGraw- Hill Medical publishing Divison, , page 525,2005

[6]. Elliott PM, Inman WHW: Volume of liquor amnii in normal and abnormal pregnancy. Lancet 2: 835, 1961

[7]. Elsafi Ahmed Abdalla,Caroline Edward Ayad, Rian Omer Massaaed Elbasher, Amel Gadal.Evaluation of amniotic fluid volume among Sudanese Diabetic patientsin third trimester using ultrasound. International journal of medical imaging.Vol. 1, No.2, ,pp.2631. 2013

[8]. E. F. Magann, A. T. Sandlin, and S. T. Ounpraseuth, "Amniotic fluid and the clinical relevance of the sonographically estimated amniotic fluid volume: oligohydramnios," Journal of Ultrasound in Medicine, vol. 30, no. 11, pp. 1573-1585, 2011.

[9]. T. R. Moore and J. E. Cayle, "The amniotic fluid index in normal human pregnancy," American Journal of Obstetrics \& Gynecology, vol. 162, no. 5, pp. 1168-1173, 1990.

[10]. Lu SC, Chang CH, Yu CH, Chang FM. Reappraisal of normal amniotic fluid index in an Asian population. Taiwan J Obstet Gynecol. Sep;46(3):260-3. 2007

[11]. Philip N. Baker. Obstetrics by Ten Teachers.18 the Edition , Manchester.UK: HODER ARNOLD ; 2000

[12]. R. A. Brace and E. J. Wolf, "Normal amniotic fluid volume changes throughout pregnancy," The American Journal of Obstetrics and Gynecology, vol. 161, no. 2, pp. 382-388, 1989.

[13]. S. M. Lee, S. K. Park, S. S. Shim, J. K. Jun, J. S. Park, an d H. C . Sy n,“ Measurement of fetal urine production by threedimensional ultrasonography in normal pregnancy," Ultrasound in Obstetrics and Gynecology, 30,3, pp.281-286,2007

[14]. Sherer, D.M. A Review of Amniotic Fluid Dynamics and the Enigma of Isolated Oligohydramnios. American Journal of Perinatology,19(5),253-266,(2002). 